ORIGINAL ARTICLE

\title{
Evaluation of anaerobic threshold values and maximal oxygen consumption of elite Turkish football teams
}

\author{
MEHMET BEYAZ1 \\ ${ }^{1}$ Assistant Professor, School of Physical Education and Sport, Istanbul Gelişim University, Istanbul, Turkey, mbeyaz@gelisim.edutr, Orcid \\ Id: 0000-0001-6778-6253
}

\begin{abstract}
In this study, it was aimed to determine, compare and evaluate the anaerobic threshold values and maximal oxygen consumption of the football players in the teams competing in the Turkcell Super league.

The causal screening model was used in the study, and a total of 67 athletes from 3 teams in the Turkcell Super League participated. The names of the teams are coded as Team A, Team B and Team C. Data collection was performed using SensorMedics 29 c ergospirometry with the breath by breath method of maximal oxygen consumption. Heart rate values were recorded instantly using Polar watch. The V-Slope method was used for the anaerobic threshold value. While SPSS 25.0 package program was used for statistical evaluation, One Way ANOVA analysis was applied to compare 3 teams.

As a result of the statistical evaluation, it was determined that there was a statistically significant difference between the teams in endurance training (heart rate), anaerobic threshold (heart rate), recovery (heart rate), and interval training (heart rate) parameters, however there was no statistically significant difference between the teams in VO2max values.

As a result, although there is no statistically significant difference between the VO2max values between the teams, it is concluded that the athletes with higher values are more advantageous in other parameters.

Keywords: Football, anaerobic threshold, maximal oxygen
\end{abstract}

\section{INTRODUCTION}

It is known that football is a sports branch that is watched with interest and preferred all around the world. The physical, physiological, psychological and technical-tactical needs of football have been increasing from the past to the present, and sports scientists and athletic performance experts are trying to contribute to this branch with current studies in order to increase the performance of football players.

In today's football, it is said that elite football players can cover a total distance of 9-14 km during a match. However, it is stated that while football players spend most of the competitions doing low-intensity activities (standing, walking, running, etc.), high-intensity efforts (sprint, etc.) constitute approximately $10 \%$ of the distance covered. For this reason, the improved aerobic endurance and anaerobic endurance performances of football players have great importance ${ }^{1}$ It is stated that one of the endurance characteristics that determine the performance of football players is the anaerobic threshold.

The anaerobic threshold is defined as the point at which the transition from aerobic metabolism to anaerobic metabolism occurs during exercises with increasing intensity. It is also said that the anaerobic threshold is a threshold that indicates the steady-state of maximum lactate, which is equivalent to the blood lactate concentration, the second return point for ventilation, oxygen uptake, and the heart rate deviation point ${ }^{2}$. Although the energy requirement during a football match is met by aerobic metabolism, it is stated that one of the most decisive parameters affecting the outcome of the match is anaerobic metabolism ${ }^{3}$. During high-intensity contractions, lactate along with $\mathrm{H}+$ occurs in the muscles, and lactate elimination from plasma increases. Once elimination is saturated, blood lactate concentrations (CL) begin to rise when production exceeds clearance. It is stated that the exercise intensity corresponding to this increase in blood lactate concentrations (CL) in the blood lactate curve (CLE) is an important criterion for endurance performance since it is associated with the transition from aerobic to anaerobic training ${ }^{4}$. Therewithal, another parameter that determines the endurance performance of football players is the maximal oxygen consumption capacity which was proven in the studies.

Maximum oxygen uptake (VO2max) and lactate threshold (LA) are often used to evaluate the physiological impact of endurance training and to predict endurance performances for elite athletes ${ }^{5}$. In other words, VO2max measurements, which are defined as the highest oxygen uptake that can be achieved during dynamic exercises with large muscle groups, can be defined as measurements that are commonly used to evaluate an individual's oxygen intake, transport and utilization capacity ${ }^{6}$. Although it varies individually in elite football players during a football match, it is stated that maximal oxygen use is $75 \%$ of $\mathrm{VO}^{2} \mathrm{max}^{7}$. It also shows that aerobic endurance is related to performance in football, along with the fact that a 90-minute football match should be considered a long performance. A high VO2max, lactate threshold and good running economy can be considered performance factors in football ${ }^{8}$. Based on this information, it is seen that the determination, development and continuity of endurance, which is one of the criteria of success in the football branch, is of great importance for each football player. Furthermore, it is thought that it is important to determine individual values with pre-season endurance tests in order to bring the endurance characteristics of the football players to the highest level and to ensure that they reach the desired high level performance. In the study, it was aimed to determine and evaluate the anaerobic threshold values and maximal oxygen consumption of the football players in the teams competing in the Turkcell Super league. 


\section{METHODS}

Research model: The causal screening model was used in the research. In this direction, the causal comparison method of the survey model, which aims to determine the causes of an existing/naturally occurring situation or event and the variables affecting these causes or the results of an effect was used ${ }^{9}$.

Research Group: A total of 67 football players from 3 teams competing in the Turkcell Super league participated in the research. The names of the teams are kept confidential and coded as Team A (19 football players), Team B (20 football players) and Team C (28 football players).

Data Collection: The maximum oxygen consumption of the athletes was carried out with the breath by breath method using SensorMedics 29 c ergospirometry. The exercise tests of the athletes were carried out using the "athlete test protocol" treadmill. In the athlete test protocol, the test was started at a speed of $9 \mathrm{~km} / \mathrm{h}$ without incline and the treadmill speed was increased by $1 \mathrm{~km} / \mathrm{h}$ every minute and the athlete was asked to continue with maximum effort. Heart rate measurements were carried out by instantaneous measurements with a Polar watch and were instantly recorded in the Vmax program. Anaerobic threshold heart rate measurements of the athletes were carried out manually using the V-Slope method.

V-Slope Method: This method, based on the expression of VCO2 in terms of $\mathrm{V} 6 \mathrm{O} 2$ and originally proposed by Beaver et al. in 1986, allows the detection of VT. The calculation method is based on the work done by Schnheider et al. in 1993. VT is determined at the intersection point of 2 lines determined by a linear regression expressing VCO2 in VO2. The intersection point of the 2 lines formed as a result of the regression is moved across the entire data set range and the value that minimizes the residual sum of squares value is determined as $\mathrm{VT}^{10}$.

Statistical analysis: The data obtained in the study were transferred to the electronic environment and given as mean and standard deviation. For the normality test of the data, skewness and kurtosis values were checked with the Kolmogorov-Smirnov test. One way ANOVA was used for the comparison of the teams with the normal distribution of the data, and a value of $p<0.05$ was accepted as the level of significance. SPSS 25.0 Package Program was used for statistical analysis.

Table 1. Results of Skewness- Kurtosis and KolmogorovSmirnov Test Significance Level of The Data

\begin{tabular}{|l|l|l|l|l|}
\hline Variables & $\mathrm{N}$ & Skewness & Kurtosis & $\mathrm{p}$ \\
\hline VO2 Max (ml/kg/min) & 67 &,- 347 &,- 273 &, 402 \\
\hline $\begin{array}{l}\text { Endurance Training Heart Rate } \\
\text { (beats/min) }\end{array}$ & 67 &,- 282 &,- 990 &, 021 \\
\hline $\begin{array}{l}\text { Anaerobic Threshold Heart Rate } \\
\text { (beats/min) }\end{array}$ & 67 &,- 295 &,- 969 &, 026 \\
\hline $\begin{array}{l}\text { Recovery Heart Rate } \\
\text { (beats/min) }\end{array}$ & 67 &,- 293 &,- 972 &, 023 \\
\hline $\begin{array}{l}\text { Interval Training Heart } \\
\text { Rate(beats/min) }\end{array}$ & 67 &,- 294 &,- 952 &, 026 \\
\hline
\end{tabular}

When the Kolmogorov-Smirnov test results are examined in Table 1, it is observed that there are no deviations from normality in the scores obtained from the data. The application of Kolmogorov-Smirnov analysis is only one of the methods used to determine the normal distribution of data. When the normal distribution curves are examined; It was determined that there were no extreme deviations from normality. It was determined that there were no deviations from normality in the data in the range of \pm 1.5 and the data showed a normal distribution.

Table 2. Descriptive Analysis of Data

\begin{tabular}{|l|l|l|l|l|}
\hline Variables & Teams & Min & Max & Mean \pm Ss \\
\hline \multirow{3}{*}{ VO2 Max (ml/kg/min) } & Team A & 43,60 & 66,70 & $54,89 \pm 5,73$ \\
\cline { 2 - 5 } & Team B & 38,40 & 60,70 & $51,28 \pm 7,14$ \\
\cline { 2 - 5 } & Team C & 36,00 & 58,90 & $51,27 \pm 5,63$ \\
\hline \multirow{3}{*}{ Endurance Training Heart Rate (beats/min) } & Team A & 130,00 & 158,00 & $141,00 \pm 9,20$ \\
\cline { 2 - 5 } & Team B & 128,00 & 160,00 & $144,00 \pm 7,48$ \\
\cline { 2 - 5 } & Team C & 137,00 & 165,00 & $155,21 \pm 5,76$ \\
\hline \multirow{3}{*}{ Anaerobic Threshold Heart Rate (beats/min) } & Team A & 144,00 & 176,00 & $156,36 \pm 10,29$ \\
\cline { 2 - 5 } & Team B & 142,00 & 178,00 & $160,05 \pm 8,32$ \\
\cline { 2 - 5 } & Team C & 152,00 & 183,00 & $172,39 \pm 6,41$ \\
\hline \multirow{3}{*}{ Recovery Heart Rate (beats/min) } & Team A & 94,00 & 114,00 & $101,63 \pm 6,54$ \\
\cline { 2 - 5 } & Team B & 92,00 & 116,00 & $104,00 \pm 5,47$ \\
\cline { 2 - 5 } & Team C & 99,00 & 119,00 & $112,07 \pm 4,14$ \\
\hline \multirow{3}{*}{ Interval Training Heart Rate(beats/min) } & Team A & 151,00 & 185,00 & $164,26 \pm 10,88$ \\
\cline { 2 - 5 } & Team B & 149,00 & 187,00 & $168,05 \pm 8,70$ \\
\cline { 2 - 5 } & Team C & 160,00 & 192,00 & $181,10 \pm 6,76$ \\
\hline
\end{tabular}

When Table 2. is examined, the mean VO2 max value $(\mathrm{ml} / \mathrm{kg} / \mathrm{min})$ of Team A is $54.89 \pm 5.73$ and the mean of VO2 max value $(\mathrm{ml} / \mathrm{kg} / \mathrm{min})$ of Team $B$ is $51.28 \pm 7.14$, the mean of team $C$ was $51.27 \pm 5.63$. Team A's Endurance training (heart rate) average is $141.00 \pm 9.20$, Team B's Endurance training (heart rate) average is $144.00 \pm 7.48$ and Team C's Endurance training (heart rate) is ) mean was 155.21 \pm 5.76 . Team A's Anaerobic threshold (heart rate) average was 156.36 \pm 10.29 , Team B's Anaerobic threshold (heart rate) average was 160.05 \pm 8.32 , and Team C's Anaerobic threshold (heart rate) average was determined as $172.39 \pm 6.41$. Team A's Recovery (heart rate) average is $101.63 \pm 6.54$, Team B's Recovery (heart rate) average is $104.00 \pm 5.47$, and Team C's Recovery (heart rate) average was determined as $112.07 \pm 4.14$. Team A's Interval training (heart rate) average is $164.26 \pm 10.88$, Team B's Interval training (heart rate) average is $168.05 \pm 8.70$ and Team C's Interval training (heart rate) average was determined as $181.10 \pm 6.76$. 
Table 3. Evaluation of Parameters According to Teams

\begin{tabular}{|c|c|c|c|c|c|c|}
\hline Parameters & Team & $\mathrm{N}$ & Mean \pm Ss & $\mathrm{F}$ & $\mathrm{P}$ & Difference \\
\hline \multirow{3}{*}{ VO2 Max (ml/kg/min) } & Team A & 19 & $54,89 \pm 5,73$ & \multirow{3}{*}{2,355} & \multirow{3}{*}{103} & \multirow[t]{3}{*}{ - } \\
\hline & Team B & 20 & $51,28 \pm 7,14$ & & & \\
\hline & Team C & 28 & $51,27 \pm 5,63$ & & & \\
\hline \multirow{3}{*}{ Endurance Training Heart Rate (beats/min) } & Team A & 19 & $141,00 \pm 9,20$ & \multirow{3}{*}{24,825} & \multirow{3}{*}{, $000^{\star *}$} & \multirow{3}{*}{$1-3$} \\
\hline & Team B & 20 & $144,00 \pm 7,48$ & & & \\
\hline & Team C & 28 & $155,21 \pm 5,76$ & & & \\
\hline \multirow{3}{*}{ Anaerobic Threshold Heart Rate (beats/min) } & Team A & 19 & $156,36 \pm 10,29$ & \multirow{3}{*}{25,012} & \multirow{3}{*}{, $000^{* *}$} & \multirow{3}{*}{$1-3$} \\
\hline & Team B & 20 & $160,05 \pm 8,32$ & & & \\
\hline & Team C & 28 & $172,39 \pm 6,41$ & & & \\
\hline \multirow{3}{*}{ Recovery Heart Rate (beats/min) } & Team A & 19 & $101,63 \pm 6,54$ & \multirow{3}{*}{25,570} & \multirow{3}{*}{, $000^{* *}$} & \multirow{3}{*}{$1-3$} \\
\hline & Team B & 20 & $104,00 \pm 5,47$ & & & \\
\hline & Team C & 28 & $112,07 \pm 4,14$ & & & \\
\hline \multirow{3}{*}{ Interval Training Heart Rate(beats/min) } & Team A & 19 & $164,26 \pm 10,88$ & \multirow{3}{*}{25,002} & \multirow{3}{*}{, $000^{* *}$} & \multirow{3}{*}{$1-3$} \\
\hline & Team B & 20 & $168,05 \pm 8,70$ & & & \\
\hline & Team C & 28 & $181,10 \pm 6,76$ & & & \\
\hline
\end{tabular}

${ }^{\star *} \mathrm{P}<0,01$

When Table 3 is examined, it has been determined that there is a statistically significant difference in Endurance training (heart rate), Anaerobic threshold (heart rate), Recovery (heart rate) and Interval Training (Heart Rate) parameters. It is seen that the resulting difference is due to the dissimilarity between Team $A$ and Team $C$ in Endurance training (heart rate), Anaerobic threshold (heart rate), Recovery (heart rate) and Interval Training (Heart Rate) parameters $(p<0.05)$. When the VO2Max ( $\mathrm{ml} / \mathrm{kg} / \mathrm{min}$ ) parameters of the teams were evaluated, no statistically significant difference was found ( $p>0.05)$.

\section{DISCUSSION}

This study was carried out to evaluate the anaerobic threshold values and maximal oxygen consumption of Elite Turkish Football teams. When the statistical analysis results were evaluated, a statistically significant difference was found when the averages of the Endurance Training (heart rate) parameter was examined $(p<0.05)$. It is seen that this difference is between Team $A$ and Team $C$. When the studies in the literature were examined, Ruivo et al., (2016) investigated the effects of a 16-week strength training program applied to football players and found that strength training had a statistically significant difference on endurance performance $(p<0.05)^{11}$. In another study, Kırdan (2018), in his master's thesis study named "Comparison of the effects of continuous running at the beginning of training in football and 5 to 5 narrow field games on endurance development", found that there was a statistically significant difference in the parameters of endurance before and after training $(p<0.05)^{12}$. In another study, Mohr et al. (2020) determined the average heart rate of endurance training to be $160(140-180)$ in their study titled "Returning to football after Covid 19 quarantine in elite football players"13. Studies in the literature show parallelism with our study.

When the Anaerobic Threshold (heart rate) averages of the teams were examined, it was determined that there was a statistically significant difference $(p<0.05)$. It is seen that this difference is between Team A and Team C. Modric et al., (2020), in their study titled "Aerobic fitness and game performance indicators; player position characteristics and relationships in professional football players", they determined that the anaerobic threshold heart rate of the defenders was $185.26 \pm 6.20$, the heart rate of the midfielders was $180.22 \pm 10.45$, and the heart rate of the strikers was $182.82 \pm 7.28^{14}$.In another study, Metaxas and Thomas (2021), "Match running performance of elite football players": when they evaluated the effects of VO2Max- player position, they found the average anaerobic threshold (heart rate) to be $173 \pm 10.2^{15}$. In another study, Ferriera et al., (2014) analyzed the power and aerobic capacity of elite athletes of both types and different sports practitioners, while the average anaerobic threshold (heart rate) of young football players under the age of 20 was $159.17 \pm 3.66$, the average anaerobic threshold (heart rate) of professional football players was $163.42 \pm 4.21$, the average of anaerobic threshold (heart rate) of female football players was $156.17 \pm 2.76$, and the average of anaerobic threshold (heart rate) of handball players was determined as $157.91 \pm 3.51^{16}$. The studies carried out show parallelism with our study.

When the recovery (heart rate) parameter of the teams was examined, it was determined that there was a statistically significant difference between the teams $(p<0.05)$. This difference was determined to be between Team A and Team C. Akgül et al., (2015) in their study named "The effect of hydrotherapy on recovery in football players", found that active rest decreased blood lactate level and accelerated recovery compared to passive rest $(p<0.05)^{17}$. In another study, Bieuzen et al. (2012) compared the group who is using electrical blood flow technology for blood flow stimulation in recovery after highintensity interval training in elite football players and the passive resting group, and compared the group using electrical blood flow technology to the passive resting group 1 hour after the application. and found an improvement in anaerobic performance ${ }^{18}$. This result shows parallelism with our study. In addition, they found that both methods did not improve the regeneration of muscle damage and voluntary contraction ( $p>0.05)$. Kaplan and Bozkurt (2018) found that the most effective method among passive rest, active rest and massage and resting practices is active recovery ${ }^{19}$. These results differ from our study. It is thought that this difference is caused by the level of the athletes and the difference in practice.

It was determined that there was a statistically significant difference between the teams in the Interval 
Training (heart rate) parameter. It was regalutated that this difference is between Team A and Team C. Faude et al., (2013) in their study titled "High-volume running training versus high-intensity interval training in high-level young football players", they found that there was a statistically significant difference between before and after interval training (heart rate) ${ }^{20}$. In another study, Arcos et al. (2015) examined the effects of interval training versus small field games in young elite football players on some parameters and found that there was a statistically significant difference in interval training ${ }^{21}$. Wong et al. (2010) in their study titled "The effect of pre-season simultaneous muscle strength and high-intensity interval training in professional football players", the research group determined that there was a statistically significant difference in some parameters between the pre-test and post-test ${ }^{22}$. It is seen that some studies in the literature show parallelism with our study.

When the VO2Max $(\mathrm{ml} / \mathrm{kg} / \mathrm{min})$ parameters of the teams were examined, no statistically significant difference was found $(p>0.05)$. In their research titled "Comparison of some physical parameters of professional and regional amateur league football players according to leagues and positions", Söyler and Kayantaş (2020), they found that there was no significant difference between the VO2Max $(\mathrm{ml} / \mathrm{kg} / \mathrm{min})$ distance and VO2Max $(\mathrm{ml} / \mathrm{kg} / \mathrm{min})$ values of the football players participating in the study ${ }^{23}$. In another study, Soyal and Beyleroğlu (2018) investigated the effects of the preparation period training of football players and handball players on the VO2Max anaerobic threshold and isocapnic buffering phase parameters and found that there was no significant difference in the VO2Max $(\mathrm{ml} / \mathrm{kg} / \mathrm{min})$ values of football players and handball players ${ }^{6}$. These results are similar to our study. In another study, Rani and Sharma (2019) investigated the aerobic capacity and VO2 Max values of Bhutan national football team players according to their positions and found that there was a significant difference in VO2Max values ${ }^{24}$. Örer et al., (2012), in their study titled "Comparison of VO2Max levels of elite and hearing-impaired football players", they found that the mean heart rate of the 3rd league players to be $193.83 \pm 8.26$, the mean heart rate of the 1st league players to be $184.77 \pm 6.91$ and the mean heart rate of the hearing impaired football players to be $187 \pm 7.74$ and found that there was a significant difference in VO2Max values ${ }^{25}$. These results differ from our study. It is thought that this difference is due to the training levels of the athletes and the league levels they compete in.

As a result, while no statistically significant difference was found between the 3 teams in the VO2max parameter in the study, it was seen that the average of Team A was higher, although it showed that these teams were generally close to each other. Looking at the other parameters, it was determined that the values of the $A$ team were lower than the other teams in the endurance training heart rate, anaerobic threshold heart rate, recovery heart rate and interval training heart rate parameters. This can be explained by the fact that football players with high VO2max values have lower values in the parameters in which their heart rates are evaluated. According to this result, it is thought that as the oxygen capacity that is used increases, the heart rate adapts to the training in a more controlled way. In other words, it is thought that the football player with a high VO2max level will reach the maximal level later and recover faster.

\section{REFERENCES}

1. Modric, T., Versic, S., \& Sekulic, D. (2021). Does aerobic performance define match running performance among professional soccer players? A position-specific analysis. Research in Sports Medicine, 1-13.

2. Nikooie, R. (2016). Determination of anaerobic threshold by monitoring the $\mathrm{O} 2$ pulse changes in endurance cyclists. Journal of strength and conditioning research, 30(6), 17001707.

3. Stølen, T., Chamari, K., Castagna, C., \& Wisløff, U. (2005). Physiology of soccer. Sports medicine, 35(6), 501-536.

4. Heuberger, J. A., Gal, P., Stuurman, F. E., de Muinck Keizer, W. A., Mejia Miranda, Y., \& Cohen, A. F. (2018). Repeatability and predictive value of lactate threshold concepts in endurance sports. PloS one, 13(11), e0206846.

5. Torvik, P.- $\varnothing$., van den Tillaar, R., \& Iversen, G. (2020). Does the Order of Submaximal Lactate Threshold and Maximal Oxygen Uptake Testing Influence Test Outcomes? Sports, 8(6), 75.

6. Soyal, M., ve Beyleroğlu, M. (2018). The Effect of Trainings on Izokapnik Buffering Phase in Football and Handball. LAP LAMBERT Academic Publishing is a trademark of intrnational Book Market Service Ltd., member of OmniScritum Publishing Group.

7. Nilsson, J., \& Cardinale, D. (2015). Aerobic and anaerobic test performance among elite male football players in different team positions. LASE Journal of Sport Science, 6(2), 73-92.

8. Ziogas, G. G., Patras, K. N., Stergiou, N., \& Georgoulis, A. D. (2011). Velocity at lactate threshold and running economy must also be considered along with maximal oxygen uptake when testing elite soccer players during preseason. The journal of strength \& conditioning research, 25(2), 414-419.

9. Büyüköztürk, Ş. (2007). Handbook of Data Analysis for Social Sciences (8th Edition). Ankara: Pegem Yayıncilık.

10. Santos, E. L. ve Giannella-Neto, A. (2004). Comparison of Computerized Methods for Detecting The Ventilatory Thresholds. European Journal of Applied Physiology, 93(3), 315-324.

11. Ruivo, R. M., Carita, A. I., \& Pezarat-Correia, P. (2016). Effects of a 16-week strength-training program on soccer players. Science \& Sports, 31(5), e107-e113.

12. Kırdan, B. (2018). Comparison of the Effects of Continuous Running at the Beginning of Training and 5 to 5 Narrow Field Games on the Development of Endurance in Football. (Master's Thesis). İstanbul Gelişim Üniversitesi/Sağlık Bilimleri Enstitüsü, İstanbul.

13. Mohr, M., Nassis, G. P., Brito, J., Randers, M. B., Castagna, C., Parnell, D., \& Krustrup, P. (2020). Return to elite football after the COVID-19 lockdown. Managing Sport and Leisure, 1-9.

14. Modric, T., Versic, S., \& Sekulic, D. (2020). Aerobic fitness and game performance indicators in professional football players; playing position specifics and associations. Heliyon, 6(11), e05427.

15. Metaxas, T. I. (2021). Match running performance of elite soccer players: VO2max and players position influences. The Journal of Strength \& Conditioning Research, 35(1), 162-168.

16. Ferreira, R. C. A., de Barros Souza, F., Ribeiro, W., Fernandes, W. S., de Almeida Fagundes, A., Kawaguchi, L. Y. A., \& Lazo-Osorio, R. A. (2014). Analysis of Power and Aerobic Capacity in Elite Athletes of Both Genres, Practitioners of Different Sports. Advances in Physical Education, 4(04), 202. 
17. Akgül, M. Ş., \& Çakmakçi, O. (2015). The effect of hydrotherapy on recovery in football players. SPORTMETRE Journal of Physical Education and Sport Sciences, 13(2), 143-150.

18. Bieuzen, F., Pournot, H., Roulland, R., \& Hausswirth, C. (2012). Recovery after high-intensity intermittent exercise in elite soccer players using VEINOPLUS sport technology for blood-flow stimulation. Journal of athletic training, 47(5), 498-506.

19. Kaplan, D. S., \& Bozkurt, M. (2018). Investigating the Most Commonly Applied Lactate Recovery Method According to the Positions in Football. European Journal of Therapeutics, 24(4), 229-233.

20. Faude, O., Schnittker, R., Schulte-Zurhausen, R., Müller, F., \& Meyer, T. (2013). High intensity interval training vs. highvolume running training during pre-season conditioning in high-level youth football: a cross-over trial. Journal of Sports Sciences, 31(13), 1441-1450.

21. Los Arcos, A., Vázquez, J. S., Martín, J., Lerga, J., Sánchez, F., Villagra, F., \& Zulueta, J. J. (2015). Effects of small-sided games vs. interval training in aerobic fitness and physical enjoyment in young elite soccer players. PloS one, 10(9), e0137224.

22. Wong, P. L., Chaouachi, A., Chamari, K., Dellal, A., \& Wisloff, U. (2010). Effect of preseason concurrent muscular strength and high-intensity interval training in professional soccer players. The Journal of Strength \& Conditioning Research, 24(3), 653-660.

23. Söyler, M., \& Kayantas, I. (2020). Comparison of Some Physical Parameters of Professional and Regional Amateur League Footballers According to Leagues and Positions. African Educational Research Journal, 8(2), 368380.

24. Rani, A., \& Sharma, P. (2019). Dominance of Aerobic Capacity and Vo2 Max among Bhutanese National Club Footballers in Relation to Their Playing Position. History Research Journal, 5(6), 3104-3110.

25. Örer, G. E., Güzel, N. A., Açak, M., Savaş, S., \& Coşkuner, Z. (2012). Comparison of max vo2 levels of elite and deaf footballers. 